UDC 930.26(470+571):711.3

Submitted: 22.02 .2020

LBC 63.48(2)-3

Accepted: 22.05 .2020

\title{
MORPHOLOGICAL PATTERNS OF THE EARLY MEDIAEVAL POPULATION OF THE EASTERN ARAL REGION (BASED ON THE MATERIALS OF ALTYN-ASAR BURIAL SITES)
}

\author{
Maria B. Mednikova \\ Institute of Archaeology RAS, Moscow, Russian Federation \\ Anna A. Tarasova \\ Institute of Archaeology RAS, Moscow, Russian Federation \\ Olga Yu. Chechyotkina \\ Institute of Archaeology RAS, Moscow, Russian Federation
}

\begin{abstract}
Introduction. Morphological studies of ancient peoples are associated with traditions of physical anthropology classifying data of similarity and differences of appearance of humans in the past. The use of standard measurement techniques contributed to the accumulation of a data array that allows drawing conclusions about the origin and environment of paleopopulations even with a small number and preservation of skeletal material. Archaeological sites of the Jetyasar culture were investigated in the $80 \mathrm{~s}$ of the $21^{\text {st }}$ century by the Khwarism Expedition of the USSR Academy of Sciences in the low basin of the Syr Darya river. The culture originated as a result of contacts of oasis agriculturists and steppe cattle-breeders in the northern part of the Great Silk Road. The majority of material is associated with the period from the first centuries AD till the $8^{\text {th }}$ century, when local population left places due to increased aridity. According to archaeological data, during the $4^{\text {th }}-7^{\text {th }}$ centuries part of the inhabitants of the region had migrant origin and/or participated in the Great Migration to the west. The goal of the study is to evaluate the morphological diversity of the Jetyasar people during the mediaeval time. Methods and Materials. The skeletal series from Altyn-Asar 4a-t, Tompakasar, Kosasar burial sites totally represents remains of 600 individuals of different chronology. Comparative data from Southern Siberia, Middle Asia, North Caucasus and Central Europe helps to study the differentiation of the mediaeval population by basic parameters of the skeletal The paper reveals some trends which might indicate genetic relations of some Jetyasar Rroups and the possible participation in migrations. Morphological similarity of groups from Kosasar-2 and Altyn-Asar 4v burial sites with inhabitants of Mongolia and Tuva of the Hun-Sarmatian time has been detected. The patterns of physical development of people from Altyn-Asar $4 \mathrm{~m}$ necropolis confirm the hypothesis of archaeologists about their migrant origin. However, the majority of other early and later groups have morphological analogies among the earlier or synchronous population of Middle Asia (Altyn-Asar 4b, 1, d, r, g, Tompakasar). Part of the population demonstrates peculiar morphological similarity with the Avars of Central Europe (Altyn-Asar 4k, t, o).

Key words: skeletal constitution, osteometry, Eastern Aral region, Early Middle Ages, Great Migration.

Citation. Mednikova M.B., Tarasova A.A., Chechyotkina O.Yu. Morphological Patterns of the Early Mediaeval Population of the Eastern Aral Region (Based on the Materials of Altyn-Asar Burial Sites). Vestnik Volgogradskogo gosudarstvennogo universiteta. Seriya 4. Istoriya. Regionovedenie. Mezhdunarodnye otnosheniya [Science Journal of Volgograd State University. History. Area Studies. International Relations], 2020, vol. 25, no. 4, pp. 84-102. (in Russian). DOI: https://doi.org/10.15688/jvolsu4.2020.4.5
\end{abstract}




\title{
МОРФОЛОГИЧЕСКИЕ ОСОБЕННОСТИ РАННЕСРЕДНЕВЕКОВОГО НАСЕЛЕНИЯ ВОСТОЧНОГО ПРИАРАЛЬЯ (ПО МАТЕРИАЛАМ МОГИЛЬНИКОВ АЛТЫН-АСАР)
}

\author{
Мария Борисовна Медникова \\ Институт археологии РАН, г. Москва, Российская Федерация \\ Анна Анатольевна Тарасова \\ Институт археологии РАН, г. Москва, Российская Федерация \\ Ольга Юрьевна Чечеткина \\ Институт археологии РАН, г. Москва, Российская Федерация
}

\begin{abstract}
Аннотация. Морфологические исследования древних народов сопряжены с классическими традициями антропологической науки, стремившейся систематизировать данные о сходстве и различии внешнего облика представителей давно ушедших эпох. Применение стандартных измерительных методик способствовало накоплению массива данных, позволяющего даже при незначительной численности и сохранности скелетного материала строить умозаключения о происхождении и среде обитания палеопопуляций. В бассейне Нижней Сырдарьи в 80-е гг. XX в. Хорезмской экспедицией АН СССР были изучены археологические памятники джетыасарской археологической культуры, сформировавшейся благодаря контактам оазисных земледельцев и степных скотоводов на северном отрезке Великого шелкового пути. Подавляющая часть этих материалов относится к хронологическому диапазону начиная с первых веков н. э. по VIII в., когда возросшая аридность климата вынудила население покинугь эту территорию. По данным археологии, в IV-VII вв. часть обитателей Нижней Сырдарьи имела мигрантное происхождение и/или приняла участие в Великом переселении народов на запад. Целью нашей работы было рассмотрение степени морфологической неоднородности джетыасарцев в период раннего средневековья. Скелетная серия из разновременных могильников Алтын-Асар 4а-т, Томпакасар, Косасар суммарно насчитывает останки около 600 человек. Привлечение сравнительных данных с территории Южной Сибири, Средней Азии, Северного Кавказа, Центральной Европы помогает оценить дифференциацию раннесредневекового населения по основным параметрам скелетной конституции, отражающим размеры и линейные пропорции тела (метод канонического анализа). Выявлены некоторые тенденции, позволяющие предполагать генетические связи отдельных групп джетыасарского населения и их возможное участие в миграционных процессах. Установлено морфологическое сходство группы из могильника Косасар-2 и группы Алтын-Асар 4в с населением Монголии и Тувы гунно-сарматского времени. Особенности физического развития погребенных в могильнике Алтын-Асар 4м подтверждают тезис археологов об их возможном мигрантном происхождении. Но большинство ранних и поздних групп (Алтын-Асар 4б, л, д, р, г, Томпакасар) имеют морфологические аналоги в составе более раннего или синхронного населения Средней Азии. Особый интерес вызывает выявляемое на разных уровнях сходство части джетыасарского населения с аварами Центральной Европы (Алтын-Асар 4к, т, о). Вклад авторов. М.Б. Медникова производила измерения скелетных материалов и написала текст статьи. А.А. Тарасова выполнила статистическую обработку. О.Ю. Чечеткина принимала участие в обследовании материалов и работала с базами данных.
\end{abstract}

Ключевые слова: скелетная конституция, остеометрия, Восточное Приаралье, раннее средневековье, Великое переселение народов.

Цитирование. Медникова М. Б., Тарасова А. А., Чечеткина О. Ю. Морфологические особенности раннесредневекового населения Восточного Приаралья (по материалам могильников Алтын-Асар) // Вестник Волгоградского государственного университета. Серия 4, История. Регионоведение. Международные отношения. -2020. - Т. 25, № 4. - С. 84-102. - DOI: https://doi.org/10.15688/jvolsu4.2020.4.5 
Введение. В бассейне Нижней Сырдарьи начиная с середины первого тысячелетия до н. э. и вплоть до VIII в. н. э. сложилась так называемая джетыасарская археологическая культура. Ее архитектурные памятники и погребальные сооружения были изучены Хорезмской археолого-этнографической экспедицией Института этнологии и антропологии РАН (Института этнографии АН СССР) под руководством Л.М. Левиной [7].

С.П. Толстов считал это население тохарами. Он полагал, что в III-V вв. вместе с аугасиями Нижней Сырдарьи их племена подверглись влиянию гуннской культуры и языка, войдя в состав «белых гуннов» (эфталитов) $[17$, c. 196].

Л.М. Левина соотносила с данной территорией китайские летописные источники, в которых эта страна носит название Янцай, Аланья, позднее - Судэ. Носители джетыасарской культуры жили в укрепленных поселениях, строили сложные ирригационные сооружения. Они вели комплексное хозяйство, максимально используя природные ресурсы в условиях аридной зоны [6]. Обнаружение определенных предметов погребального инвентаря в могильнике Косасар-2, в частности костяных лук от жесткого седла, наряду с глиняной статуэткой с его изображением, позволило высказать предположение о проникновении в Восточное Приаралье хуннов еще в І в. до н. э. [7, c. 200-201].

К своеобразным особенностям джетыасарского населения можно отнести распространение обряда кольцевой деформации [3$5 ; 15 ; 19]$. Несмотря на обилие деформированных черепов и, следовательно, невозможность в полной мере использовать краниометрический метод, Т.П. Кияткиной удалось установить, что в этногенезе джетыасарского населения приняли участие представители южного европеоидного, другого европеоидного и монголоидного расовых компонентов [4]. Одонтологическое исследование Г.В. Рыкушиной подтверждает тезис о метисном и многокомпонентном происхождении джетыасарского населения [16]. Результаты антропологических изысканий хорошо согласуются с выводами археологов о полиэтничной джетыасарской культурной общности как о важном компоненте северного участка
Великого шелкового пути, «Аральского узла этногенеза», игравшего значительную роль в процессе активных миграций эпохи раннего средневековья [7].

Ранее по полной остеометрической программе были обследованы 2 скелетные серии из расположенных в 4 км друг от друга могильников Косасар-2 и Томпакасар [10; 13]. Серии приблизительно синхронны: они датируются самое позднее IV в. н. э. [7]. По данным археологии, в материальном комплексе могильника Косасар-2 усилено влияние инокультурных традиций. В могильнике Томпакасар аккумулированы наиболее характерные черты джетыасарской культуры. Кости мужчин, погребенных в могильнике Косасар-2, были охарактеризованы как крупные, массивные, в то время как кости мужчин Томпакасара отличаются грацильностью и снижением продольных размеров. При сопоставлении женских серий из могильников Косасар-2 и Томпакасар значимые различия не обнаружены. Скелетные размеры свидетельствуют о грацильном строении.

Рассмотрение линейных пропорций вскрыло заметные отличия в строении тела у мужчин сопоставляемых групп. Мужчины Томпакасара характеризуются относительным укорочением плечевых и бедренных костей и усиленным продольным развитием костей предплечья и голени. Такой тип строения находит ближайшие аналогии в некоторых синхронных палеопопуляциях Средней Азии [18]. Напротив, мужчины Косасара-2 по пропорциям конечностей обнаруживают определенное сходство с носителями тагарской культуры Минусинской котловины, с савроматами и сарматами Уральского региона и Поволжья, ранее объединенными в рамках единого «степного» морфологического варианта [11; 13]. Кроме того, методом канонического анализа основных остеометрических показателей в 26 мужских выборках эпохи раннего железного века и гунно-сарматского времени было выявлено особое сходство приаральских мужчин Косасара-2 и погребенных в Чандманьском могильнике северо-западной Монголии (другое, более привычное, название - Улангом), а также обитателей Тувы, похороненных в грунтовых могилах комплекса Аймырлыг XXXI [14, c. 262-263]. 
Накопление сравнительных данных по остеометрии разных палеопопуляций эпохи раннего средневековья, сформировавшихся в процессе Великого переселения народов, позволяет нам перейти к анализу антропологических материалов из раскопок джетыасарских некрополей Алтын-Асар 4а-т. Их археологическая специфика, планиграфия и стратиграфия захоронений [7] определили необходимость в рамках данной публикации рассматривать каждый могильник АлтынAcap 4 как отдельную группу населения. Цель нашей работы - оценить морфологическую дифференциацию джетыасарского населения в сравнительном освещении.

Методы и материалы. Вблизи джетыасарских городищ были выявлены некрополи, содержавшие тысячи захоронений. По стандартной остеометрической программе [1] в рамках данной работы были обследованы останки 468 человек из раскопок некрополей Алтын-Асар 4а-т (далее - AА4). Численность ранее изученных скелетных серий из раскопок могильников Томпакасар и Косасар-2 coставляла останки 53 и 77 индивидуумов соответственно [10;12;13].

Как подчеркивала руководитель раскопок Хорезмской экспедиции Л.М. Левина, каждый могильник был топографически привязан к определенному участку речного русла или его притоков [7, с. 61-67]. В отличие от других некрополей, в могильнике Косасар2 вплоть до IV в. н. э. хоронили в заболоченном грунте, на полуостровке между двумя протоками. Могильник Томпакасар также относится к первому этапу развития джетыасарской культуры (до IV в.). Некрополь Алтын-Асар 4а, по данным археологии, охватывает более продолжительный период вплоть до V-VI вв. н. э., при этом подавляющее число захоронений принадлежат первым векам н. э. Могильник АА4б преимущественно относится к II-IV вв., но несколько захоронений - к IV-V вв., V-VI векам. АA4в, локализованный напротив AA4a, отличался присутствием инокультурной керамики, что привело Л.М. Левину к заключению о погребении здесь представителей другого этноса [7]. Захоронения совершались в основном в первые века н. э., но несколько самых поздних погребений датируются V-VII веками. Не- большие некрополи АА4г, АА4д, АА4к относятся к первому этапу джетыасарской культуры - не позднее III-IV веков. Более обширный могильник АА4л относится к этому же периоду. Некрополь АА4м относится к хронологическому диапазону III-VI вв., исследованные в нем курганы отличаются от характерных для джетыасарской культуры деталями погребального обряда, инвентарем, наземным видом кургана, другим типом земляной насыпи, отсутствием окаймлявшего насыпь рва и наличием дополнительного земляного кольца по краю насыпи. Могильник АА4о смыкается с АА4л, он использовался в течение очень длительного времени, $56 \%$ могил датируется ранним этапом, оставшиеся - серединой и третьей четвертью первого тысячелетия н. э. Некрополь АA4p (соседний с АA4м) датирован IV-VII веками. Могильник АA4т преимущественно относится к IV-VI векам.

Канонический анализ остеометрических данных проводился в программе Б.А. Козинцева «CANON» с использованием усредненной корреляционной матрицы, разработанной на обширном материале европеоидных евразийских серий эпох бронзы и раннего железного века М.Б. Медниковой [8; 9].

Анализ. Морфология посткраниального скелета джетыасарского населения в сравнительном освещении. Несмотря на общую представительность джетыасарской остеологической коллекции, сохранность трубчатых костей в сериях из отдельных могильников накладывает ограничения на использование материалов в рамках межгруппового анализа (табл. 1, 2). Наиболее достоверными могут считаться данные по сериям АА4в, к, л, м, o, p, т, Косасар-2 и Томпакасар.

На первом этапе в рамках канонического анализа были рассмотрены 8 признаков, характеризующих наибольшие длины и окружности крупных сегментов конечностей, наиболее полно отражающих размеры и форму посткраниального скелета. Кроме джетыасарских материалов в этом анализе были рассмотрены материалы из раскопок могильника гунно-сарматского времени Аймырлыг XXXI с территории Тувы (подгруппы погребенных в каменных ящиках и грунтовых могилах) [2] (рис. 1, табл. 3). 


\section{МОРФОЛОГИЯ ДРЕВНИХ ПОПУЛЯЦИЙ}

Первые две канонические переменные описывают суммарно свыше 71 \% изменчивости. Первая каноническая переменная отражает морфологическую тенденцию скелетной вариабельности, связанную с существованием двух альтернативных морфологических вариантов - с грацильными и массивными диафизами плечевой, лучевой, бедренной и большеберцовой костей. Вторая каноническая переменная выявляет закономерность, связанную с различиями линейных пропорций, а именно с удлинением или укорочением костей предплечья.

В плоскости первой и второй канонических переменных обращает на себя внимание группировка серий из могильников АА4к и л, AА4в и выборки из грунтовых могильников Аймырлыг XXXI, групп Косасар-2 и каменные ящики Аймырлыга. Выборка из могильника АА4м отчетливо обособляется от всех других серий.

На втором этапе были привлечены сравнительные материалы по Южной Сибири, Центральной и Средней Азии, Северному Кавказу, Центральной Европе [10-12; 18; 20-23]. Поскольку наиболее многочисленный блок сравнительных данных с территории Венгрии (несколько тысяч индивидуумов) включал только результаты измерений длин трубчатых костей, нам пришлось ограничиться рассмотрением четырех признаков - наибольших длин плечевой, лучевой, бедренной и большеберцовой костей.

В первом анализе рассматривались измерения, полученные для 24 выборок (рис. 2, табл. 4). Первая и вторая канонические переменные описывают свыше 78 \% накопленной изменчивости. Первый вектор отражает противопоставление крупных и миниатюрных форм, второй - различия в линейных пропорциях, связанных с длиннорукостью и коротконогостью, с одной стороны, и укорочением руки и удлинением нижней конечности - с другой. В пространстве первой и второй канонических переменных наиболее отчетливо резкое обособление сарматов из выборки Клин Яр, что подтверждает сделанный ранее вывод о чрезвычайной высокорослости позднесарматского населения на фоне средних значений, характерных для евразийского населения той эпохи [11].
Исключение из анализа мужских групп этой выборки позволяет получить более дробную картину межгрупповой дифференциации (рис. 3). Первая каноническая переменная отражает тенденцию удлинения или укорочения предплечья, бедра и голени, вторая - удлинение или укорочение верхней конечности. Первый и второй векторы описывают более 77 \% вариабельности.

Выделяются крупные, длинноногие и длиннорукие выборки германцев эпохи Великого переселения народов с территории Венгрии, Косасар-2. От них несколько отстоит, сближаясь с основным массивом, серия Алтын-Асар 4в. В левой верхней части графика (рис. 3) группируются выборки, для которых наряду с общими крупными размерами характерно относительное укорочение костей предплечья. Среди них авары с территории Австрии (Мюнхендорф), а также серии АлтынAcap 4т и к, авары из Венгрии, Алтын-Асар 40 и среднеазиатская Бабиш-Мулла.

В правоцентральной части графика объединяются выборки АА4л, б, Томпакасар и Старый Термез, серия АА4д очень близка Гурмирону. АА4м, в первом анализе обособленный от основного массива джетыасарских групп, по продольным размерам и линейным пропорциям находится в центре поля их изменчивости. Группы AA4p и г демонстрируют крайнее положение среди миниатюрных выборок благодаря выраженному укорочению плечевой кости. Противоположную позицию занимают миниатюрные группы алан Клин Яра и таштыкцев Абаканского Чаатаса, для которых характерно относительное удлинение всех сегментов верхней конечности.

Последний вариант канонического анализа проводился по 4 признакам при рассмотрении 25 мужских групп, включая выборки гунно-сарматского времени из Тувы (рис. 4). В целом получена картина, повторяющая ранее изложенные результаты. Выборка Косасар-2 особенно близка серии погребенных в грунтовых могилах Аймырлыг XXXI. Тувинская серия из каменных ящиков располагается между Абаканским Чаатасом и группой Алтын-Асар 4к.

Картина дифференциации женского населения получена в рамках канонического анализа 19 выборок по 4 признакам продольного 
развития костей конечностей (рис. 5, табл. 5). Первая каноническая переменная описывает варианты, связанные с укорочением и удлинением плечевой кости и удлинением / укорочением предплечья. Вторая каноническая переменная противопоставляет крупные и миниатюрные варианты скелетной конституции. Первые две канонические переменные описывают свыше $92 \%$ накопленной изменчивости.

Как и при рассмотрении мужских выборок, наиболее удаленными друг от друга оказываются представительницы алан Клин Яра и германские женщины эпохи Великого переселения народов с территории Венгрии. По значениям первого вектора бинарную оппозицию составляют сарматки Клин Яра и женщины группы AA4p. Примечательно, что различия между сарматками Клин Яра и сарматками римского времени с территории Венгрии не так велики, как между мужчинами указанных групп. Женщины «венгерских» аваров близки представительницам джетыасарского населения из выборок Косасар-2, Томпакасар, АА4д, в меньшей степени - AА4т. Женщины АА4в и л по форме и размерам скелета близки представительницам тагарской культуры из Знаменки в Минусинской котловине. Женщины из выборок АА4б, о, м, р отстоят от других джетыасарцев благодаря выраженному удлинению плечевой кости.

Обсуждение. Остеометрические исследования древнего населения Евразийского континента позволили установить главные закономерности географической и эпохальной изменчивости скелетной конституции. Например, было показано обособление обитателей степной полосы Евразии по признакам посткраниального скелета от жителей лесостепной и лесной ландшафтных зон начиная с эпох энеолита и бронзы [11]. В эпохи бронзы и раннего железа в пределах степного коридора широкое распространение получил морфологический вариант, характеризуемый относительной плотностью строения, крупными или средними размерами, сбалансированными пропорциями. Сходные особенности посткраниальной конституции проявляются вне зависимости от расовой и этнической принадлежности, что позволило нам высказать предположение об адаптивной природе данного варианта строения, приспособительного по от- ношению к условиям проживания в определенной ландшафтной зоне.

Обитатели среднеазиатского региона характеризуются на фоне однородного и стабильного «степного» комплекса бо́льшим морфологическим разнообразием.

Начиная с эпох энеолита и бронзы в Средней Азии сосуществовали по меньшей мере два морфологических варианта, различавшихся по линейным пропорциям скелета [11].

Первый вариант представлен в скелетных сериях из Кара-Депе, Геоксюра и Кокчи-3. По продольным размерам длинных костей эти группы приближаются к высокорослым степнякам эпохи бронзы (ямникам и минусинским афанасьевцам), отличаясь от них абсолютным и относительным укорочением предплечья. Выборки из Саппалитепе и Джаркутана, напротив, характеризуются относительным укорочением плечевой кости. Общая черта мужских выборок в этот период состояла в относительном удлинении костей нижней конечности, и особенно костей голени, то есть в акцентированном развитии конституциональных особенностей, адаптационных по отношению к аридному, теплому климату с невысокой годовой амплитудой температур.

В гунно-сарматское время обитатели Средней Азии морфологически по-прежнему обособлены от степняков. Как правило, они грацильнее, но наиболее важными представляются сохраняющиеся различия в линейных пропорциях. Остеологические выборки из КараКудука (IV-II вв. до н. э.), Гурмирона, Старого Термеза (II-V вв. н. э.) в разной степени демонстрируют относительное укорочение плечевой кости и удлинение предплечья и голени. Фрагментарные останки из Бабиш-Мулла (IVII вв. до н. э.) и Калалы-Гыр (II-V вв. н. э.), повидимому, принадлежат населению с иными скелетными особенностями, напоминая миниатюрный «степной» вариант. Своеобразно строение останков из Дальверзинтепа с удлиненными верхними и укороченными за счет костей голени нижними конечностями.

В контексте уже имеющихся данных важно исследовать конституциональную изменчивость оазисных культур, особенно на севере Средней Азии и в тех районах Восточного Туркестана, где, по данным исторических источников, осуществлялись контакты 
кочевников и оседлых земледельческих групп. Изучение скелетной морфологии древних обитателей Восточного Приаралья является в этой связи одной из первоочередных задач.

Исследование скелетной серии, происходящей из джетыасарского могильника Косасар-2, позволило установить морфологическую принадлежность мужской части этого населения крупному «степному» варианту [10; 21]. Несколько иные тенденции обнаружила более грацильная женская выборка. Мужчины Томпакасара отличались от мужчин Косасара-2 относительным укорочением плечевых и бедренных костей и усиленным продольным развитием дистальных сегментов, что находит ближайшие аналогии с некоторыми синхронными группами населения Средней Азии. Таким образом, можно было предполагать, что уже на раннем этапе бытования джетыасарской культуры в бассейне Нижней Сырдарьи у ее носителей было распространено как минимум два варианта скелетной конституции.

Рассмотрение антропологических материалов из раскопок джетыасарских могильников Алтын-Асар 4 позволяет уточнить картину дифференциации типов телосложения. При этом значительная часть выборок (АА4a, б, в, г, Д, к, л) относятся к раннему этапу - вплоть до IV в., как и выборки Косасар-2 и Томпакаcap. Могильники AA4p и т - поздние (IVVII вв., IV-VI вв.). Серия из могильника АA4o охватывает очень обширный хронологический интервал и в перспективе нуждается в разбивке на подгруппы, прежде всего путем прямого радиоуглеродного датирования костных останков. Промежуточное положение занимает выборка из раскопок могильника АлтынАсар 4м, появляющегося примерно за век до начала гуннской экспансии на запад.

Обособленное местоположение большинства некрополей позволило нам рассматривать происходящие из них антропологические материалы в качестве отдельных комплексов. Уже первый канонический анализ мужских подгрупп по 8 признакам, характеризующим длины трубчатых костей и их диаметры, показал неоднородность этого населения (рис. 1). В нем обращает на себя внимание обособление ранних групп АА4к, л, в, б и поздних групп АА4о, т. При этом поздняя группа АA4p примыкает к кластеру перечислен- ных выше ранних групп, что может свидетельствовать о преемственности части населения. Особо подчеркнем, что этот анализ, учитывавший степень диафизарной массивности трубчатых костей, выявил сходство мужчин Косасара-2 с мужчинами из каменных ящиков Аймырлыга, а мужчин Алтын-Асара 4в с мужчинами того же тувинского могильника, погребенными в грунтовых ямах. Это наблюдение подкрепляется данными археологии о присутствии в материальном комплексе этих могильников инокультурных черт. Аналогично группа мужчин АA4M, отличающаяся от всех остальных, происходит из могильника, оставленного, по мнению Л.М. Левиной [7], людьми мигрантного происхождения.

Канонический анализ мужских групп на более широком сравнительном фоне, в основу которого положены только длины сегментов конечностей, вновь выявляет сходство серии Косасар-2 с гунно-сарматскими обитателями Южной Сибири (на этот раз с выборкой из грунтовых могил), а также противопоставляет две морфологические совокупности: джетыасарцев Алтын-Асара 4в, б, л, м, д, p, г, Томпакасара наряду со старым Термезом и аварские группы Австрии и Венгрии вместе с Алтын-Асаром 4к, т, о и Бабиш-Муллой.

Картина дифференциации женского населения иная. Материалы из могильников Коcacap-2, Томпакасар, Алтын-Асар 4д и т могут быть причислены к единому субстрату джетыасарского населения, по физическому типу близкого аваркам Венгрии. Женщины АА4в и л неожиданно сближаются с обитательницами Минусинской котловины раннего железного века, что может косвенно свидетельствовать об участии в их происхождении степного населения. Наиболее дисперсны женские группы АА4о, м, р. Учитывая, что они более поздние, нельзя отвергать фактор возможных миграций в бассейн Нижней Сырдарьи не только мужского, но и женского населения.

Результаты. Результаты остеометрического исследования говорят о высоком морфологическом разнообразии джетыасарского населения, что позволяет вновь, вслед за данными краниологии и одонтологии, подтвердить тезис о неоднородности его антропологического состава. Поскольку возможности приме- 
нения к этим материалам краниометрического метода ограничены из-за сильно выраженной искусственной деформации большинства черепов, исследование посткраниального скелета становится особо важным источником информации. В рамках нашей работы представлены итоги межгруппового анализа серий из джетыасарских могильников с привлечением сравнительных данных эпохи раннего средневековья с территории Центральной и Средней Азии, Северного Кавказа, Центральной Европы. В итоге выявлены некоторые тенденции, позволяющие предполагать генетические связи отдельных групп джетыасарского населения и их возможное участие в миграционных процессах эпохи Великого переселения народов. Эти тенденции подкрепляются данными археологии о присутствии разных инокультурных групп в джетыасарском социуме. Так, на новом уровне подтверждается морфологическое сходство группы из могильника Косасар-2 с населением Монголии и Тувы гунно-сарматского времени. В меньшей степени выявляется связь со степным населением Южной Сибири людей, погребенных в могильнике Алтын-Асар 4в. Особенности физического развития погребенных в могильнике АА4м подтверждают тезис археологов об их возможном мигрантном происхождении. В то же время большинство ранних и поздних групп (Алтын-Асар 4б, л, д, p, г, Томпакасар) имеют морфологические аналоги в составе более раннего или синхронного населения Средней Азии. Особый интерес вызывает выявляемое на разных уровнях сходство части джетыасарского и, шире, среднеазиатского населения с аварами Центральной Европы (Алтын-Асар 4к, т, о, Бабиш-Мулла). Эти данные могут задать вектор будущих палеогенетических исследований, способных пролить свет на сложные вопросы происхождения многокомпонентного джетыасарского населения и его возможного участия в глобальных миграциях первого тысячелетия нашей эры. 


\section{ПРИЛОЖЕНИЕ}

Таблица 1. Морфологическая характеристика мужчин джетыасарской культуры (нумерация признаков по Р. Мартину)

Table 1. Morphological patterns of males of the Jetyasar culture (numbers of features according to R. Martin)

\begin{tabular}{|c|c|c|c|c|c|c|c|c|c|c|c|c|}
\hline \multirow{2}{*}{\begin{tabular}{|l|} 
Группа \\
правая сторона \\
\end{tabular}} & \multicolumn{3}{|c|}{$\mathrm{H} 1$} & \multicolumn{3}{|c|}{$\mathrm{H} 7$} & \multicolumn{3}{|c|}{ R1 } & \multicolumn{3}{|c|}{ R3 } \\
\hline & $n$ & $x$ & s & n & $x$ & s & $n$ & $x$ & s & $n$ & $x$ & s \\
\hline A & 3 & 319 & 18.8 & 3 & 63.3 & 4.04 & 3 & 242 & 8.74 & 3 & 41.3 & 2.31 \\
\hline 5 & 5 & 320.2 & 13.61 & 5 & 63.8 & 1.3 & 4 & 248.8 & 4.646 & 4 & 39.75 & 2.5 \\
\hline B & 12 & 325 & 15.8 & 12 & 65 & 4.5 & 8 & 250 & 13.6 & 8 & 40.4 & 3.34 \\
\hline$\Gamma$ & 1 & 309 & - & 1 & 70 & - & 2 & 253 & 12.73 & 2 & 45 & 4.243 \\
\hline Д & 3 & 311.7 & 9.866 & 3 & 58.33 & 1.528 & 3 & 241 & 6.56 & 3 & 37.3 & 2.52 \\
\hline$E$ & 2 & 328 & 1.414 & 2 & 70 & 2.83 & 1 & 246 & - & 1 & 41 & - \\
\hline$\nVdash$ & 1 & 310 & - & 1 & 69 & - & 1 & 243 & - & 1 & 43 & - \\
\hline$n$ & - & - & - & - & - & - & 1 & 235 & - & 1 & 42 & - \\
\hline $\mathrm{K}$ & 5 & 323 & 20.5 & 5 & 61.8 & 4.82 & 4 & 246 & 18.4 & 4 & 38 & 4 \\
\hline л & 15 & 319.1 & 18.72 & 15 & 64.1 & 2.79 & 15 & 258.3 & 50.47 & 15 & 41.13 & 2.669 \\
\hline M & 5 & 317 & 11 & 5 & 65.2 & 3.11 & 2 & 242 & 9.9 & 2 & 46 & 5.66 \\
\hline 0 & 13 & 323.4 & 24.76 & 13 & 63.54 & 4.054 & 10 & 242.3 & 8.367 & 10 & 41.4 & 2.796 \\
\hline$P$ & 9 & 314.1 & 28.99 & 9 & 64.33 & 5.244 & 8 & 248.8 & 10.12 & 8 & 42.25 & 5.036 \\
\hline $\mathrm{T}$ & 11 & 326.5 & 30.61 & 11 & 64 & 4.449 & 8 & 241.3 & 12.53 & 8 & 41.3 & 2.87 \\
\hline Kocacap 2 & 13 & 332,7 & 11.8 & 14 & 68,4 & 4.3 & 10 & 256,4 & 9.1 & 10 & 44,8 & 1.5 \\
\hline Томпакасар & 8 & 317,87 & & 8 & 64,5 & & 8 & 251,8 & & 8 & 41,3 & \\
\hline
\end{tabular}

Продолжение таблицы 1

Continuation of Table 1

\begin{tabular}{|c|c|c|c|c|c|c|c|c|c|c|c|c|}
\hline \multirow{2}{*}{\begin{tabular}{|l|} 
Группа \\
правая сторона \\
\end{tabular}} & \multicolumn{3}{|c|}{ F1 } & \multicolumn{3}{|c|}{ F8 } & \multicolumn{3}{|c|}{ T1 } & \multicolumn{3}{|c|}{$\mathrm{T} 10 \mathrm{~b}$} \\
\hline & $n$ & $x$ & s & $n$ & $x$ & s & $n$ & $x$ & $\mathrm{~s}$ & $n$ & $x$ & s \\
\hline A & 7 & 423 & 27 & 7 & 85 & 5.6 & 7 & 352 & 14.9 & 7 & 73.29 & 5.619 \\
\hline 5 & 4 & 457.75 & 23.114 & 4 & 88.5 & 3.317 & 5 & 368.8 & 12.05 & 5 & 73 & 5.24 \\
\hline$B$ & 14 & 433.9 & 48.99 & 14 & 89 & 5.831 & 8 & 376.4 & 23.15 & 8 & 74.13 & 5.489 \\
\hline$\Gamma$ & 2 & 460.5 & 23.33 & 2 & 93 & 4.24 & 3 & 371 & 6 & 3 & 76.7 & 6.35 \\
\hline Д & 1 & 446 & - & 1 & 83 & - & 1 & 363 & - & 1 & 65 & - \\
\hline$E$ & 1 & 463 & - & 1 & 96 & - & - & - & - & 1 & 81 & - \\
\hline$\dddot{K}$ & - & - & - & - & - & - & 1 & 346 & - & 1 & 72 & - \\
\hline n & 1 & 435 & - & 1 & 88 & - & - & - & - & - & - & - \\
\hline$K$ & 6 & 426.8 & 19.79 & 6 & 89.17 & 8.472 & 4 & 355.3 & 17.31 & 4 & 72.25 & 7.5 \\
\hline Л & 14 & 446.9 & 29.11 & 14 & 89.4 & 4.83 & 12 & 360 & 18.01 & 12 & 72.67 & 2.309 \\
\hline$M$ & 3 & 452 & 15 & 3 & 94 & 4 & 3 & 370 & 16.8 & 3 & 80.3 & 2.52 \\
\hline 0 & 9 & 445.6 & 20.57 & 9 & 87.33 & 6 & 8 & 365 & 20.85 & 8 & 72.8 & 5.06 \\
\hline P & 8 & 460.5 & 14.122 & 8 & 93.38 & 4.926 & 6 & 371 & 8.42 & 6 & 74.7 & 4.8 \\
\hline $\mathrm{T}$ & 7 & 442 & 21.5 & 7 & 89.14 & 7.71 & 9 & 355.2 & 14.6 & 9 & 72.4 & 3.64 \\
\hline Kocacap 2 & 18 & 457,7 & 21.8 & 19 & 91 & 4.2 & 18 & 373,1 & 13.5 & 21 & 75 & 3.2 \\
\hline Томпакасар & 8 & 446 & & 8 & 86,25 & & 8 & 370 & & 8 & 72,37 & \\
\hline
\end{tabular}


Продолжение таблицы 1

\section{Continuation of Table 1}

\begin{tabular}{|c|c|c|c|c|c|c|c|c|c|c|c|c|}
\hline Группа & & $\mathrm{H} 1$ & & & $\mathrm{H} 7$ & & & R1 & & & R3 & \\
\hline левая сторона & & $x$ & $s$ & $n$ & $x$ & $s$ & $n$ & $x$ & s & $n$ & $x$ & $\mathrm{~s}$ \\
\hline $\mathrm{A}$ & 8 & 311 & 18.3 & 8 & 62 & 5.8 & 8 & 245 & 11 & 8 & 41.6 & 4.03 \\
\hline 5 & 5 & 331 & 5.36 & 5 & 65 & 2.121 & 7 & 256.4 & 13.3 & 7 & 42.29 & 2.984 \\
\hline$B$ & 9 & 306 & 40.9 & 9 & 62.4 & 3.64 & 8 & 247 & 18.3 & 8 & 42 & 4.986 \\
\hline r & - & - & - & - & - & - & - & - & - & - & - & - \\
\hline Д & 1 & 297 & - & 1 & 57 & - & 1 & 242 & - & 1 & 39 & - \\
\hline Ж & 1 & 310 & - & 1 & 71 & - & 1 & 242 & - & 1 & 42 & - \\
\hline$n$ & 1 & 314 & - & 1 & 59 & - & 1 & 232 & - & 1 & 39 & - \\
\hline K & 2 & 316.5 & 30.41 & 2 & 61 & 4.24 & 3 & 259 & 21.8 & 3 & 39 & 3.606 \\
\hline л & 10 & 322 & 15 & 10 & 62.3 & 3.20 & 14 & 242.8 & 19.67 & 14 & 40.2 & 2.64 \\
\hline$M$ & 4 & 318 & 12.8 & 4 & 62.75 & 0.957 & 4 & 246 & 8.54 & 4 & 41.5 & 2.38 \\
\hline 0 & 8 & 326 & 22.95 & 8 & 64.4 & 4.41 & 9 & 245.3 & 11.58 & 9 & 42.2 & 2.33 \\
\hline $\mathrm{P}$ & 3 & 337 & 27.87 & 3 & 64.67 & 4.509 & 4 & 261.5 & 14.8 & 4 & 41.5 & 1.73 \\
\hline$T$ & 10 & 317.9 & 16.7 & 10 & 63.8 & 4.077 & 8 & 245.1 & 18.47 & 8 & 41.38 & 3.114 \\
\hline Kocacap 2 & 11 & \begin{tabular}{|l|}
330.4 \\
\end{tabular} & 15.8 & 15 & 64.9 & 3.5 & 11 & 255.4 & 10.5 & 14 & 43.1 & 1.8 \\
\hline
\end{tabular}

\section{Окончание таблищы 1}

End of Table 1

\begin{tabular}{|c|c|c|c|c|c|c|c|c|c|c|c|c|}
\hline Группа & & F1 & & & F8 & & & $\mathrm{T} 1$ & & & T10b & \\
\hline левая сторона & & $x$ & s & $n$ & $x$ & $s$ & n & $x$ & $s$ & $n$ & $x$ & $s$ \\
\hline$A$ & 1 & 486 & & 1 & 87 & & 4 & 365 & 27.2 & 4 & 75 & 6.055 \\
\hline 5 & 5 & 451 & 12.92 & 5 & 95.4 & 5.367 & 6 & 370 & 12.55 & 6 & 75.67 & 6.743 \\
\hline$B$ & 6 & 458 & 25.77 & 6 & 92 & 3.1 & 6 & 377 & 12.07 & 6 & 74.67 & 3.67 \\
\hline$\Gamma$ & 1 & 451 & - & 1 & 92 & - & - & - & - & - & - & - \\
\hline Д & 2 & 429 & 7.071 & 2 & 87 & 11.31 & 1 & 338 & & 1 & 72 & - \\
\hline Ж & - & - & - & - & - & - & - & - & - & - & - & - \\
\hline n & 1 & 440 & - & 1 & 84 & - & - & - & - & - & - & - \\
\hline K & 4 & 427.8 & 24.14 & 4 & 87.5 & 10.2 & 5 & 350.2 & 16.33 & 5 & 70.2 & 8.5 \\
\hline ת & 11 & 449 & 15.7 & 11 & 90.1 & 3.02 & 9 & 354 & 14.9 & 10 & 73.3 & 4.111 \\
\hline$M$ & 5 & 438 & 25.6 & 5 & 88 & 3.536 & 4 & 348 & 19.95 & 4 & 75 & 8.60 \\
\hline 0 & 12 & 445.7 & 14.48 & 12 & 85 & 16.8 & 14 & 364 & 14.3 & 14 & 74.1 & 4.24 \\
\hline$P$ & 3 & 476.3 & 19.76 & 3 & 76 & 33.3 & 4 & 395 & 24.6 & 4 & 76 & 3.464 \\
\hline$T$ & 8 & 453.3 & 31.61 & 8 & 91.88 & 7.511 & 10 & 363.6 & 21.35 & 10 & 72.9 & 3.755 \\
\hline Kocacap 2 & 17 & 460.3 & 18.5 & 18 & 26.4 & 2.2 & 18 & 372.8 & 12.3 & 18 & 74.2 & 3.5 \\
\hline
\end{tabular}




\section{МОРФОЛОГИЯ ДРЕВНИХ ПОПУЛЯЦИЙ}

Таблица 2. Морфологическая характеристика женщин джетыасарской культуры (нумерация признаков по Р. Мартину)

Table 2. Morphological patterns of females of the Jetyasar culture (numbers of features according to R. Martin)

\begin{tabular}{|c|c|c|c|c|c|c|c|c|c|c|c|c|}
\hline Грүппа & & $\mathrm{H} 1$ & & & $\mathrm{H} 7$ & & & R1 & & & R3 & \\
\hline правая сторгона & & $x$ & S & $n$ & $x$ & $S$ & $n$ & $x$ & s & n & $x$ & s \\
\hline A & 9 & 281 & 21.8 & 9 & 79.1 & 77.3 & 9 & 201 & 55.2 & 9 & 55.2 & 61.1 \\
\hline 5 & 6 & 296 & 13.6 & 6 & 51.3 & 2.8 & 3 & 235 & 4.04 & 3 & 31.3 & 2.89 \\
\hline$B$ & 10 & 290.7 & 9.96 & 10 & 53.7 & 1.88 & 5 & 215.8 & 11.1 & 5 & 33.8 & 3.89 \\
\hline 5 & 2 & 281.5 & 3.53 & 2 & 51 & 0 & 1 & 375 & - & 1 & 34 & 一 \\
\hline Д & 1 & 300 & - & 1 & 56 & - & 1 & 222 & - & 1 & 33 & - \\
\hline$E$ & 1 & 281 & - & 1 & 53 & - & 1 & 207 & - & 1 & 37 & - \\
\hline и & 2 & 310.5 & 2.12 & 2 & 56 & 1.41 & 1 & 231 & - & 1 & 35 & - \\
\hline ת & 12 & 284.2 & 15.1 & 12 & 53.2 & 4.37 & 7 & 219.7 & 13.52 & 7 & 34.3 & 3.2 \\
\hline$M$ & 3 & 285 & 10 & 3 & 52.7 & 3.06 & 3 & 237 & 31.1 & 3 & 33.33 & 0.57 \\
\hline 0 & 12 & 288.8 & 16.73 & 12 & 53.42 & 4.2 & 9 & 228.56 & 26.57 & 9 & 34.88 & 1.83 \\
\hline $\mathrm{P}$ & 9 & 296.3 & 14.07 & 9 & 54.4 & 3.43 & 7 & 244.6 & 32.89 & 7 & 33.86 & 2.61 \\
\hline$T$ & 5 & 295 & 11.9 & 5 & 53.6 & 1.14 & 3 & 228 & 7.57 & 3 & 36 & 2.65 \\
\hline Kocacap 2 & 12 & 297.8 & 14.9 & 16 & 54.6 & 2.7 & 8 & 226 & 8.7 & 11 & 35.1 & 2 \\
\hline
\end{tabular}

Продолжение таблиць 2

Continuation of Table 2

\begin{tabular}{|c|c|c|c|c|c|c|c|c|c|c|c|c|}
\hline Группа & \multicolumn{3}{|c|}{ F1 } & \multicolumn{3}{|c|}{ F8 } & \multicolumn{3}{|c|}{$\mathrm{T} 1$} & \multicolumn{3}{|c|}{$\mathrm{T} 10 \mathrm{~b}$} \\
\hline правая сторгона & & $x$ & $s$ & $\mathrm{n}$ & $x$ & $s$ & $\mathrm{n}$ & $x$ & $s$ & $n$ & $x$ & $\mathrm{~s}$ \\
\hline$A$ & 9 & 387.6 & 10.99 & 9 & 71.9 & 4.86 & 10 & 322.7 & 14 & 10 & 61.7 & 5.27 \\
\hline 5 & 7 & 406 & 18.9 & 6 & 75.5 & 5.08 & 4 & 346 & 16 & 4 & 63.5 & 2.38 \\
\hline B & 3 & 389 & 34.9 & 3 & 72 & 6.55 & 4 & 327.8 & 13 & 4 & 63.5 & 4.93 \\
\hline$\Gamma$ & 1 & 390 & - & 1 & 69 & - & 2 & 323.5 & 9.19 & 2 & 61 & 5.65 \\
\hline Д & 1 & 400 & - & 1 & 74 & - & 1 & 328 & - & 2 & 70 & 7.07 \\
\hline$E$ & - & - & - & - & - & - & - & - & - & - & - & - \\
\hline U & - & - & - & - & - & - & 1 & 346 & - & 1 & 64 & - \\
\hline ת & 14 & 387.4 & 33.95 & 14 & 72.64 & 5.9 & 16 & 328 & 18.3 & 16 & 61.44 & 4.61 \\
\hline$M$ & 3 & 407.3 & 16.5 & 3 & 78.33 & 4.72 & 5 & 325 & 12.73 & 5 & 60.8 & 5.11 \\
\hline 0 & 11 & 393.3 & 17.74 & 11 & 71 & 4.83 & 11 & 326.1 & 10.97 & 11 & 60.5 & 3.72 \\
\hline $\mathrm{P}$ & 9 & 398.9 & 14.39 & 9 & 72 & 3.27 & 10 & 329 & 15.7 & 10 & 60.4 & 5.25 \\
\hline$T$ & 5 & 403.6 & 20.48 & 5 & 73 & 4.18 & 5 & 325 & 15.08 & 5 & 60.6 & 1.14 \\
\hline Kocacap 2 & 17 & 405.2 & 17.3 & 19 & 75.7 & 4.9 & 11 & 331.4 & 19.6 & 17 & 62.8 & 4.4 \\
\hline
\end{tabular}


Морфологические особенности раннесредневекового населения Восточного Приаралья

Продолжение таблицы 2

\section{Continuation of Table 2}

\begin{tabular}{|c|c|c|c|c|c|c|c|c|c|c|c|c|}
\hline Группа & & $\mathrm{H} 1$ & & & $\mathrm{H} 7$ & & & R1 & & & R3 & \\
\hline левая сторона & & $x$ & $s$ & $n$ & $x$ & $s$ & $n$ & $x$ & $s$ & $\mathrm{n}$ & $x$ & 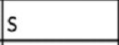 \\
\hline A & 8 & 288 & 11.5 & 9 & 53.8 & 4.35 & 8 & 238 & 27.9 & 8 & 40.6 & 16.9 \\
\hline 5 & 3 & 284.3 & 23.97 & 3 & 52 & 1.73 & 5 & 216 & 16.4 & 5 & 32 & 2.74 \\
\hline B & 3 & 279 & 25.5 & 3 & 53 & 3.61 & 6 & 223.7 & 27.21 & 6 & 35.83 & 4.07 \\
\hline$\Gamma$ & 2 & 290 & 7.78 & 2 & 53 & 2.83 & - & - & - & - & - & - \\
\hline Д & 1 & 324 & - & 1 & 57 & - & - & - & - & - & - & - \\
\hline$E$ & - & - & - & - & - & - & - & - & - & - & - & - \\
\hline 3 & 1 & 286 & - & 1 & 51 & - & 1 & 228 & - & 1 & 33 & - \\
\hline n & 2 & 289 & 19.8 & 2 & 50 & 5.65 & 2 & 220 & 7.07 & 2 & 33.5 & 3.54 \\
\hline$K$ & - & - & - & - & - & - & - & - & - & - & - & - \\
\hline л & 14 & 284.9 & 14.17 & 14 & 51.3 & 3.95 & 16 & 222.5 & 20.19 & 16 & 34.1 & 3.97 \\
\hline$M$ & 6 & 287 & 10.7 & 6 & 54.7 & 5.47 & 6 & 255 & 31.1 & 6 & 34.3 & 2.16 \\
\hline C & - & - & 一 & - & - & - & - & - & - & - & - & - \\
\hline 0 & 10 & 282.2 & 15.11 & 10 & 51.4 & 22.2 & 6 & 224.2 & 28.78 & 6 & 34.4 & 3.29 \\
\hline$P$ & 4 & 283 & 12.5 & 4 & 52.3 & 4.57 & 3 & 215 & 9 & 3 & 32.7 & 1.53 \\
\hline $\mathrm{T}$ & 4 & 289 & 10.6 & 4 & 52.75 & 1.5 & 2 & 209 & 5.66 & 2 & 33.5 & 0.71 \\
\hline Kocacap 2 & 13 & 293.2 & 13.6 & 17 & 53.9 & 3.1 & 12 & 222.6 & 12.4 & 14 & 34.5 & 1.8 \\
\hline
\end{tabular}

\section{Окончание таблищы 2}

End of Table 2

\begin{tabular}{|c|c|c|c|c|c|c|c|c|c|c|c|c|}
\hline Группа & & F1 & & & F8 & & & $\mathrm{T} 1$ & & & $\mathrm{~T} 10 \mathrm{~b}$ & \\
\hline левая сторона & & $x$ & s & $\mathrm{n}$ & $x$ & $s$ & $n$ & $x$ & $\mathrm{~s}$ & $n$ & $x$ & $\mathrm{~s}$ \\
\hline A & 9 & 394 & 16.7 & 9 & 72.89 & 4.54 & 4 & 313.8 & 16.19 & 4 & 58.5 & 3.7 \\
\hline 5 & 2 & 386 & 28.3 & 2 & 71 & 7.07 & 3 & 321 & 23.5 & 3 & 60.3 & 3.06 \\
\hline$B$ & 8 & 392.4 & 15.8 & 8 & 72.1 & 4.49 & 6 & 330 & 14.2 & 6 & 60 & 4.15 \\
\hline 「 & 2 & 390.5 & 7.77 & 2 & 86 & 8.49 & - & - & - & - & - & - \\
\hline Д & 1 & 405 & - & 1 & 73 & - & 1 & 328 & - & 1 & 65 & \\
\hline$E$ & 1 & 379 & - & 1 & 70 & - & - & - & - & - & - & - \\
\hline 3 & 1 & 405 & - & 1 & 65 & - & 1 & 334 & - & 1 & 54 & - \\
\hline$n$ & 2 & 408 & 7.07 & 2 & 73 & 9.9 & 1 & 343 & - & 1 & 62 & - \\
\hline K & 1 & 410 & & 1 & 70 & - & - & - & - & - & - & - \\
\hline Л & 9 & 379 & 22.3 & 9 & 69.6 & 4.61 & 7 & 316 & 14.2 & 7 & 58.29 & 5.93 \\
\hline$M$ & 5 & 388.8 & 2.49 & 5 & 70.6 & 3.44 & 4 & 314 & 8.75 & 4 & \begin{tabular}{|l|}
59.5 \\
\end{tabular} & 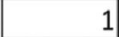 \\
\hline C & - & - & - & - & - & - & 1 & 295 & - & 1 & 57 & - \\
\hline 0 & 9 & 382.4 & 45.35 & 9 & 71.7 & 6.4 & 7 & 315 & 19.1 & 7 & 59.7 & 4.82 \\
\hline
\end{tabular}




\section{МОРФОЛОГИЯ ДРЕВНИХ ПОПУЛЯЦИЙ}

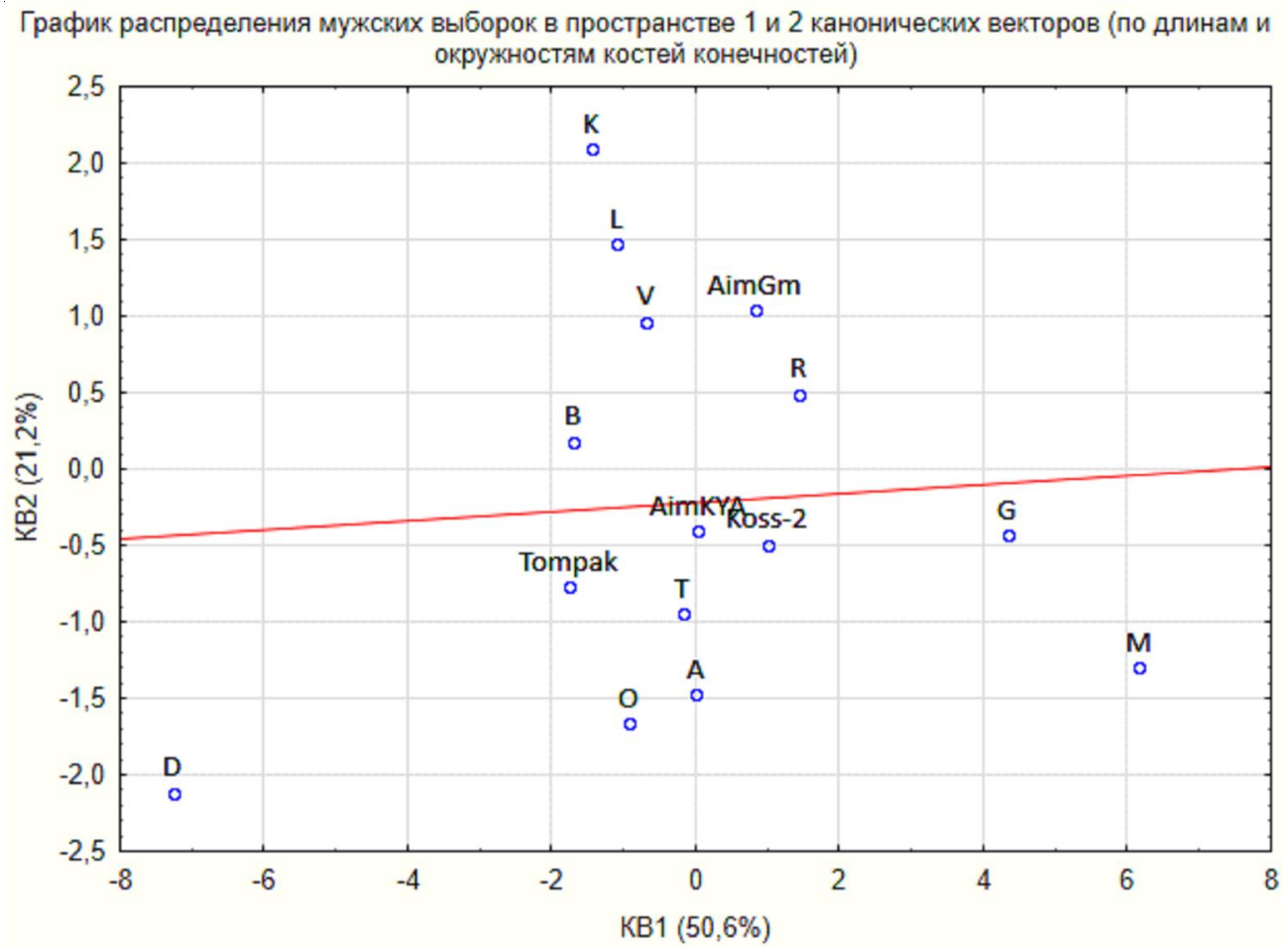

Рис. 1. Результаты канонического анализа межгрупповой изменчивости длин

и окружностей трубчатых костей в плоскости первой и второй канонических переменных. Мужчины

Fig. 1. Results of the canonic analysis of the intra-group variability of lenghts and perimeters of tubular bones. First and second canonic vectors. Males

\section{Таблица 3. Нагрузки векторов канонических переменных. Мужчины. 8 признаков}

\section{Table 3. Loads of canonic vectors. Males. 8 features}

\begin{tabular}{|l|r|r|r|r|r|}
\hline Признак & \multicolumn{1}{|c|}{ КВ1 } & \multicolumn{1}{c|}{ КВ2 } & \multicolumn{1}{c|}{ КВ3 } & \multicolumn{1}{c|}{ КВ4 } & \multicolumn{1}{c|}{ КВ5 } \\
\hline H1 & 0,002648 & 0,285110 & $-0,524266$ & $-0,121385$ & 0,527863 \\
\hline H7 & 0,760105 & 0,177334 & 0,509298 & $-0,215883$ & 0,126339 \\
\hline R1 & 0,160503 & 0,592210 & 0,511771 & $-0,018361$ & 0,194526 \\
\hline R3 & 0,887415 & $-0,158532$ & 0,317445 & $-0,136070$ & 0,175422 \\
\hline F1 & 0,300817 & $-0,055537$ & 0,506801 & 0,569613 & 0,005587 \\
\hline F8 & 0,839060 & 0,391865 & 0,140181 & 0,056633 & $-0,135685$ \\
\hline T1 & 0,263451 & 0,066008 & 0,407147 & 0,436988 & 0,118378 \\
\hline T10b & 0,965108 & 0,178389 & 0,086529 & $-0,369504$ & 0,220302 \\
\hline
\end{tabular}


Морфологические особенности раннесредневекового населения Восточного Приаралья

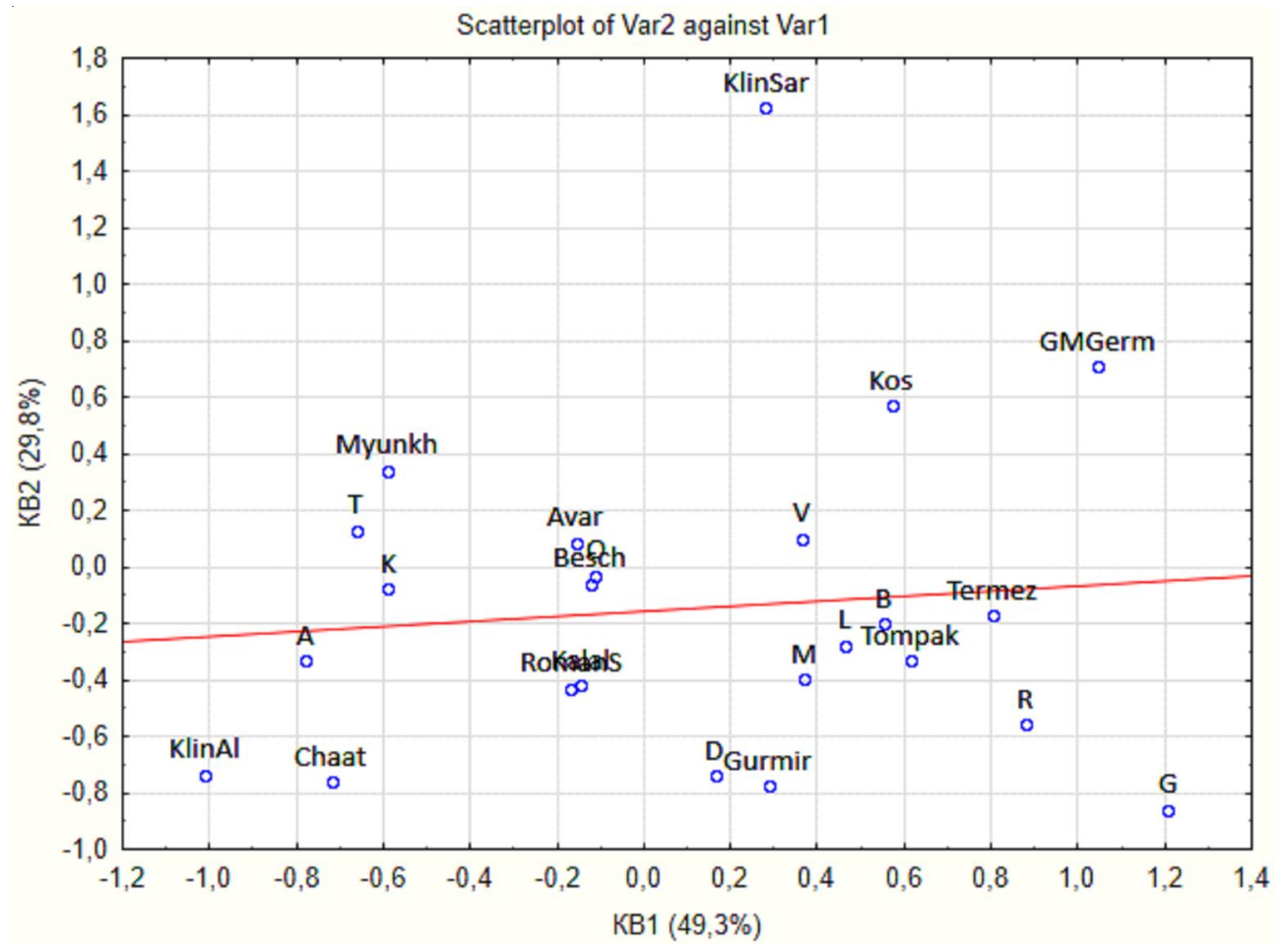

Рис. 2. Результаты канонического анализа межгрупповой изменчивости длин трубчатых костей посткраниального скелета в плоскости первой и второй канонических переменных. Мужчины. 24 выборки Fig. 2. Results of the canonic analysis of the intra-group variability of lenghts of postcranial skeleton tubular bones. First and second canonic vectors. Males. 24 samples

\section{Таблица 4. Нагрузки векторов канонических переменных. Мужчины. 4 признака,} 24 группы

Table 4. Loads of canonic vectors. Males. 4 features, 24 samples

\begin{tabular}{|l|c|r|c|}
\hline Признак & КВ1 & \multicolumn{1}{c|}{ КВ2 } & КB3 \\
\hline H1 & 0,960540 & $-0,233754$ & 0,249359 \\
\hline R1 & 0,908915 & $-0,493820$ & 0,210963 \\
\hline F1 & 0,946878 & 0,101417 & 0,033134 \\
\hline T1 & 0,966313 & 0,077376 & 0,447561 \\
\hline
\end{tabular}




\section{МОРФОЛОГИЯ ДРЕВНИХ ПОПУЛЯЦИЙ}

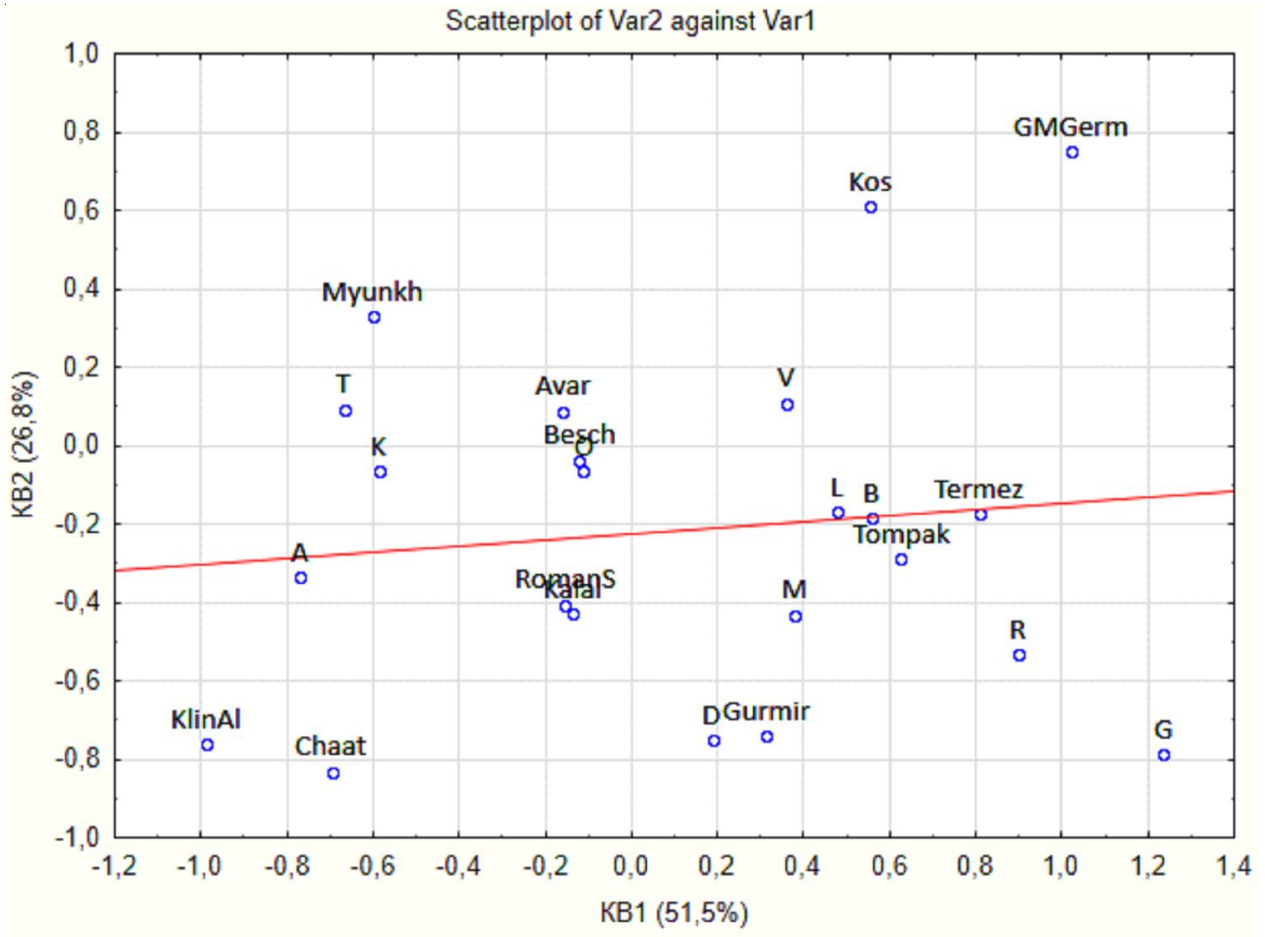

Рис. 3. Результаты канонического анализа межгрупповой изменчивости длин трубчатых костей посткраниального скелета в плоскости первой и второй канонических переменных. Мужчины. 23 выборки Fig. 3. Results of the canonic analysis of the intra-group variability of lenghts of postcranial skeleton tubular bones. First and second canonic vectors. Males. 23 samples

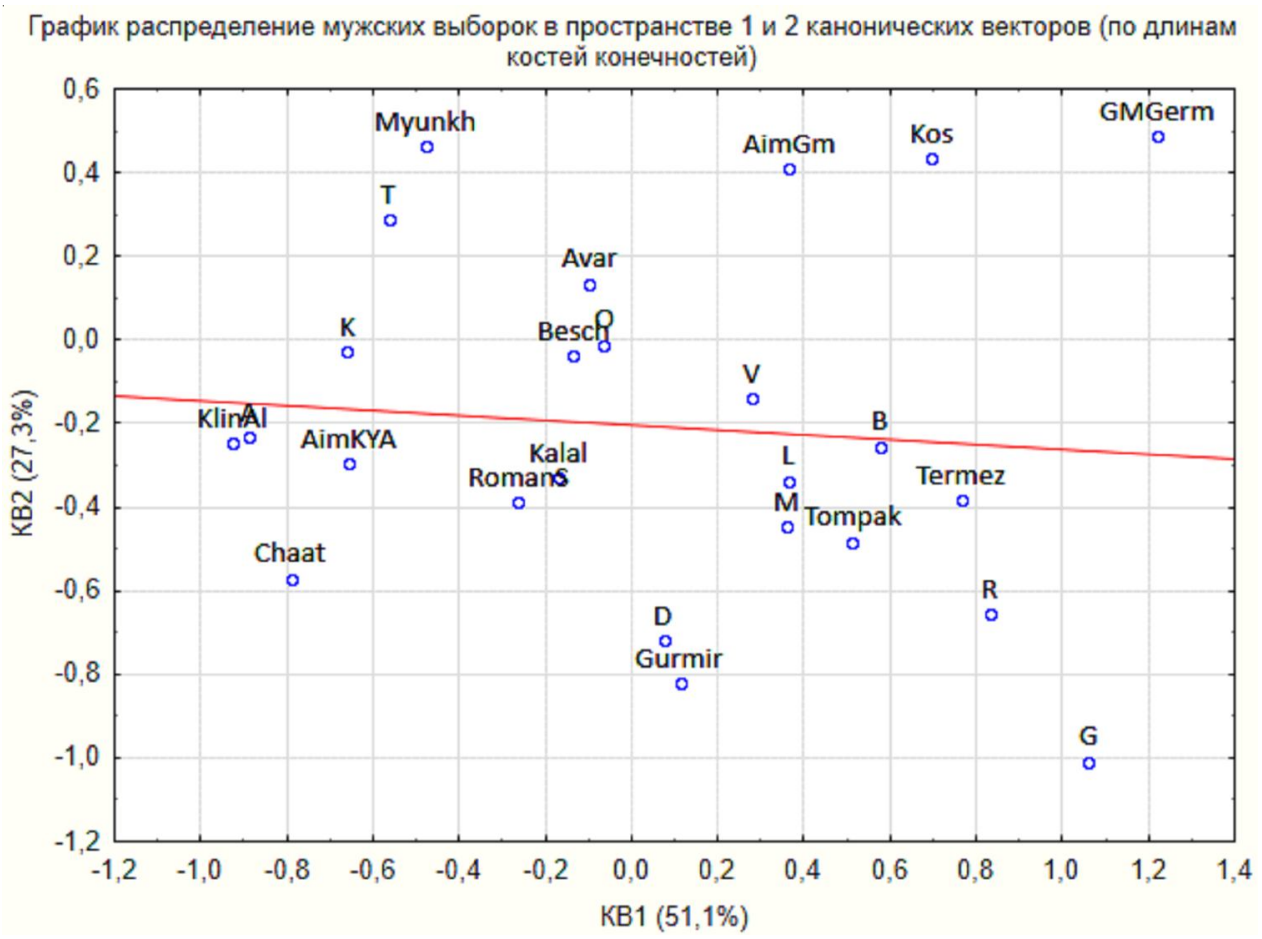

Рис. 4. Результаты канонического анализа межгрупповой изменчивости длин трубчатых костей посткраниального скелета в плоскости первой и второй канонических переменных. Мужчины. 25 выборок Fig. 4. Results of the canonic analysis of the intra-group variability of lenghts of postcranial skeleton tubular bones. First and second canonic vectors. Males. 25 samples 
Морфологические особенности раннесредневекового населения Восточного Приаралья

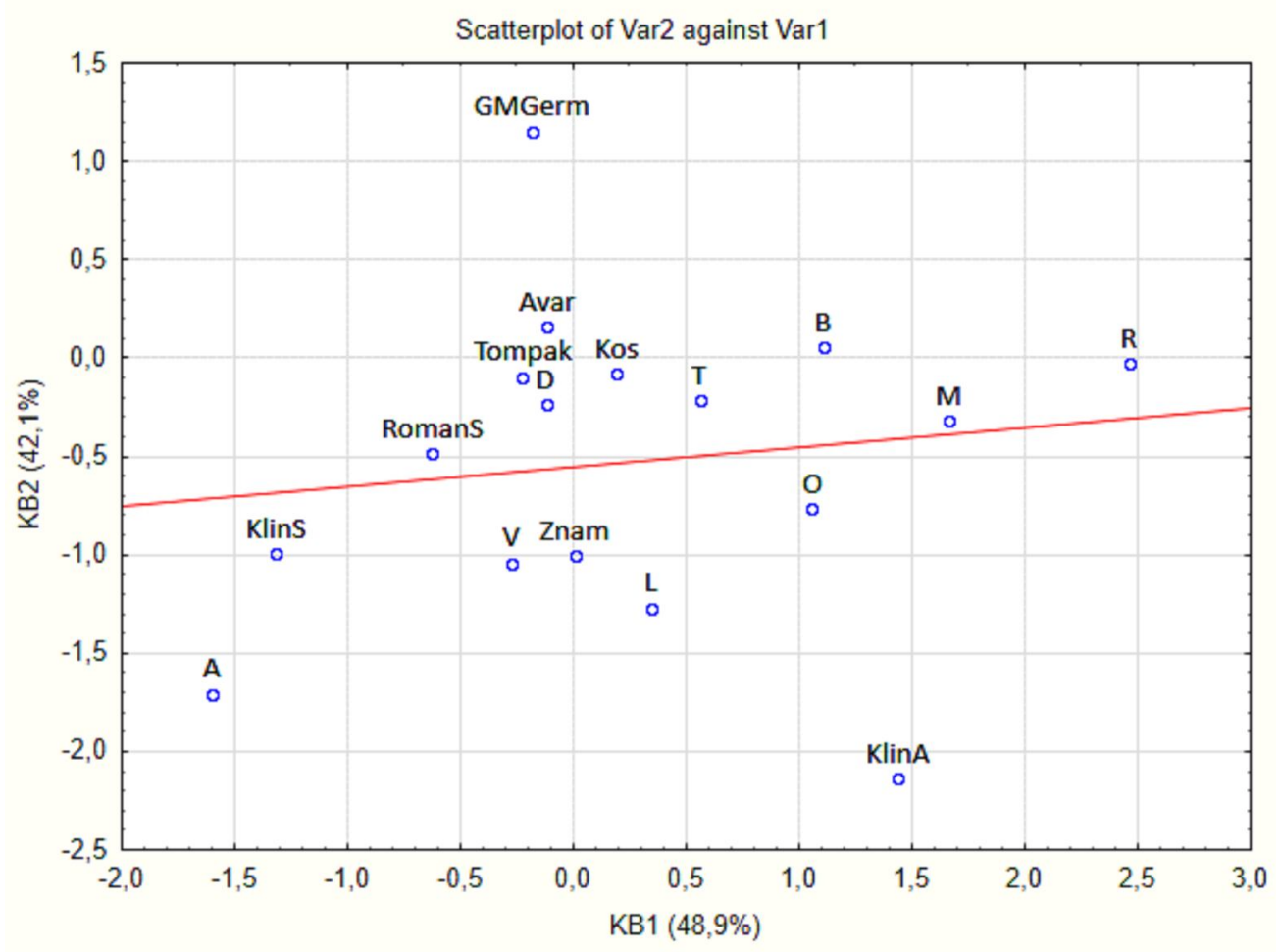

Рис. 5. Результаты канонического анализа межгрупповой изменчивости длин трубчатых костей посткраниального скелета в плоскости первой и второй канонических переменных. Женщины. 19 выборок Fig. 5. Results of the canonic analysis of the intra-group variability of lenghts of postcranial skeleton tubular bones. First and second canonic vectors. Females. 19 samples

\section{Таблииа 5. Нагрузки векторов канонических переменных. Женщины. 4 признака,} 19 групा

Table 5. Loads of canonic vectors. Females. 4 features, 19 samples

\begin{tabular}{|l|c|c|c|}
\hline Признак & KB1 & KB2 & KB3 \\
\hline H1 & $-0,018579$ & 0,989300 & $-0,186707$ \\
\hline R1 & 0,744148 & 0,559865 & $-0,575945$ \\
\hline F1 & 0,685310 & 0,168224 & 0,430336 \\
\hline T1 & 0,875925 & 0,391901 & $-0,069901$ \\
\hline
\end{tabular}




\section{СПИСОК ЛИТЕРАТУРЫ}

1. Алексеев, В. П. Остеометрия. Методика антропологических исследований / В. П. Алексеев. М. : Наука, 1966. - 251 с.

2. Богданова, В. И. Палеоантропологические материалы гунно-сарматского времени из Центральной Тувы / В. И. Богданова, А. Б. Радзюн // Новые коллекции и исследования по антропологии и археологии : сб. Музея антропологии и этнографии. - СПб. : Наука, 1991. - Т. 44. - С. 55-100.

3. Бужилова, А. П. Древнее население (палеопатологические аспекты исследования) / А. П. Бужилова. - М. : ИА РАН, 1995. - 189 с.

4. Кияткина, Т. П. Краниологический материал из склепов могильников Алтынасар 4, Томпакаcap, Косасар / Т. П. Кияткина // Низовья Сырдарьи в древности. Вып. 3. Джетыасарская культура. Ч. 1. М. : Ин-т этнологии и антропологии РАН, 1993. C. 224-242.

5. Кияткина, Т. П. Краниологические материалы из могильников Косасар 2 и Косасар 3 / Т. П. Кияткина // Низовья Сырдарьи в древности. Вып. 3. Джетыасарская культура. Ч. 2. - М. : Ин-т этнологии и антропологии РАН, 1993. - С. 206-247.

6. Левина, Л. М. Динамика ирригации и древних русел Кувандарьи в урочище Джетыасара (Восточное Приаралье) / Л. М. Левина, А. В. Птичников // Аральский кризис (историко-географическая ретроспектива). - М. : Ин-т этнологии и антропологии АН СССР, 1991. - С. 142-160.

7. Левина, Л. М. Этнокультурная история Восточного Приаралья. І тысячелетие до н. э. - I тысячелетие н. э. / Л. М. Левина. - М. : Вост. лит. РАН, 1996. $-396 \mathrm{c}$.

8. Медникова, М. Б. Антропология древнего населения Южной Сибири по данным посткраниального скелета (в связи с проблемами палеоэкологии). В 2 т. Т. 1 : дис. ... канд. биол. наук / Медникова Мария Борисовна. - М., 1993. - 230 с.

9. Медникова, М.Б. Антропология древнего населения Южной Сибири по данным посткраниального скелета (в связи с проблемами палеоэкологии) В 2 т. Т. 2 : дис. ... канд. биол. наук / Медникова Мария Борисовна. - М., 1993. - 190 с.

10. Медникова, М. Б. Древнее население Восточного Приаралья по данным остеометрии (по материалам могильника Косасар-2) / М. Б. Медникова // Низовья Сырдарьи в древности. Вып. 3. - М. : Ин-т этнологии и антропологии РАН, 1993. - С. 248-267.

11. Медникова, М. Б. Древние скотоводы Южной Сибири: палеоэкологическая реконструкция по данным антропологии / М. Б. Медникова. - М. : ИА PAH, 1995. - $220 \mathrm{c}$.

12. Медникова, М. Б. Остеометрическая методика в биоархеологических реконструкциях / М. Б. Мед- никова // Историческая экология человека. Методика биологических исследований. - М. : Старый Сад, 1998. - С. 33-87.

13. Медникова, М. Б. Антропо-экологические исследования древнего населения Восточного Приаралья / М. Б. Медникова // Горизонты антропологии : тр. Междунар. науч. конф. памяти акад. В.П. Алексеева (Москва, Салтыковка, 20-22 сентября 1994 г.). - М. : Наука, 2003. - С. 513-518.

14. Медникова, М. Б. Палеоэкология Центральной Азии по данным антропологии / М. Б. Медникова // Антропоэкология Центральной Азии. - М. : Науч. мир, 2005. - С. 256-289.

15. Медникова, М. Б. Феномен искусственной деформации головы: евразийский контекст / М. Б. Медникова // Искусственная деформация головы человека в прошлом Евразии. OPUS : Междисциплинарные исследования в археологии. Вып. 5. - М. : ИА РАН, 2006.-C. 206-229.

16. Рыкушина, Г. В. Материалы по одонтологии Джетыасарской культуры. Грунтовые погребения могильников Косасар 2, Косасар 3, Томпакасар, Бедаикасар / Г. В. Рыкушина // Низовья Сырдарьи в древности. Вып. 3. Джетыасарская культура. Ч. 2. - М. : Ин-т этнологии и антропологии РАН, 1993. - C. 195-205.

17. Толстов, С. П. По древним дельтам Окса и Яксарта / С. П. Толстов. - М. : Изд-во вост. лит., 1962. $324 \mathrm{c}$.

18. Ходжайов, Т. К. Этнические процессы в Средней Азии в период средневековья / Т. К. Ходжайов. - Ташкент : Фан, 1987. - 207 с.

19. Шведчикова, Т. Ю. К вопросу о распространении обычая искусственной деформации головы у древнего населения Восточного Приаралья / Т. Ю. Шведчикова // Вестник Московского университета. Серия XXIII. Антропология. 2009. - № 1. - С. 78-84.

20. Berner, M. Anthropologische Auswertung des Avarischen Graberfeldes von Munchendorf/M. Berner, H. Kritscher, J. Szilvassy // Awaren Furshungen. Band 2. - Wien : Institut fur Ur- und Fruhgeschichte, 1992. - S. 1025-1193.

21. Buzhilova, A. P. An Ancient Population from the Eastern Aral Region: Palaeodemography, Osteometry, Growth Arrest / A. P. Buzhilova, M. B. Mednikova // Homo. - 1999. - Vol. 50 (1). - P. 66-79.

22. Ery, K., Length of Limb Bones and Stature in Ancient Populations in the Carpatian Basin / K. Ery. Budapest : Humanbiologia Budapestinensis, 1998. -88 p.

23. The Human Bones from Klin-Yar III and IV / A. P. Buzhilova, M. V. Dobrovolskaya, M. B. Mednikova [et al.] // Ritual, Society and Population at Klin-Yar (North Caucasus) Excavations 1994-1996 in the Iron Age to Early Medieval Cemetery. - Berlin : Verlag Dr. Rudolf Habelt GmbH., 2018. - P. 134-183. 


\section{REFERENCES}

1. Alekseev V.P. Osteometriya. Metodika antropologicheskikh issledovaniy [Osteometry. Technique of Anthropological Research]. Moscow, Nauka Publ., 1966. 251 p.

2. Bogdanova V.I., Radzyun A.B. Paleoantropologicheskie materialy gunno-sarmatskogo vremeni iz Tsentralnoy Tuvy [Palaeoantropological Materials of the Hun-Sarmatian Time from Central Tuva]. Novye kollektsii $i$ issledovaniya po antropologii $i$ arkheologii: sb. Muzeya antropologii $i$ etnografii [New Collections and Studies on Anthropology and Archaeology. Collection of the Museum of Anthropology and Ethnography]. Saint Petersburg, 1991, vol. 44, pp. 55-100.

3. Buzhilova A.P. Drevnee naselenie (paleopatologicheskie aspekty issledovaniya) [Ancient Population (Palaeopathological Aspects of Study)]. Moscow, IA RAN. 189 p.

4. Kiyatkina T.P. Kraniologicheskiy material iz sklepov mogilnikov Altynasar 4, Tompakasar, Kosasar [Craniological Material from Altyn-Asar 4, Tompakasar, Kosasar Tombs]. Nizovya Syrdaryi v drevnosti. Vyp. 3. Dzhetyasarskaya kultura. Ch. 1 [Low Flow of the Syrdarya River in Antiquity. Iss. 3. Jetyasar Culture. Part 1]. Moscow, Institut etnologii i antropologii RAN, 1993, pp. 224-242.

5. Kiyatkina T.P. Kraniologicheskie materialy iz mogilnikov Kosasar 2 i Kosasar 3 [Craniological Materials from Kosasar 2 and Kosasar 3 Burials]. Nizovya Syrdaryi v drevnosti. Vyp. 3. Dzhetyasarskaya kultura. Ch. 2 [Low Flow of the Syrdarya River in Antiquity. Iss. 3. Jetyasar Culture. Part 2]. Moscow, Institut etnologii i antropologii RAN, 1993, pp. 206-247.

6. Levina L.M., Ptichnikov A.V. Dinamika irrigatsii i drevnikh rusel Kuvandaryi v urochishche Dzhetyasara (Vostochnoe Priaralye) [Dynamics of Irrigation and Ancient Water Flows of Kuvandarya River in Jetyasar Valley (Eastern Aral Region)]. Aralskiy krizis (istoriko-geograficheskaya retrospektiva) [Aral Crisis (Historical-Geographical Retospection]. Moscow, 1991, pp.142-160

7. Levina L.M. Etnokulturnaya istoriya Vostochnogo Priaralya. I tysyacheletie do n. e. I tysyacheletie n. e. [Ethnocultural History of the Eastern Aral Region. ${ }^{\text {st }}$ Millennium BC $-1{ }^{\text {st }}$ Millennium AD]. Moscow, Vostochnaya literatura RAN, 1996. 396 p.

8. Mednikova M.B. Antropologiya drevnego naseleniya Yuzhnoy Sibiri po dannym postkranialnogo skeleta (v svyazi s problemami paleoekologii). $V 2 t$. T. 1: dis. ... kand. biol. nauk [Anthropology of Ancient Population of Southern Siberia by the Data of Postcranial Skeleton (In Connection with the Problems of Paleoecology) In 2 Vols. Vol. 1. Cand. biol. sci. diss.]. Moscow, 1993. 230 p.
9. Mednikova M.B. Antropologiya drevnego naseleniya Yuzhnoy Sibiri po dannym postkranialnogo skeleta (v svyazi s problemami paleoekologii) $V 2 t$. T. 2: dis. ... kand. biol. nauk [Anthropology of Ancient Population of Southern Siberia by the Data of Postcranial Skeleton (In Connection with the Problems of Paleoecology) In 2 Vols. Vol. 2. Cand. biol. sci. diss.]. Moscow, 1993. 190 p.

10. Mednikova M.B. Drevnee naselenie Vostochnogo Priaralya po dannym osteometrii (po materialam mogilnika Kosasar-2) [Ancient Population of Eastern Aral Region According to Data of Osteometry]. Nizovya Syrdaryi v drevnosti. Vyp. 3 [Low Flow of the Syrdarya River in Antiquity. Iss. 3]. Moscow, Institut etnologii I antropologii RAN, 1993, pp. 248-267.

11. Mednikova M.B. Drevnie skotovody Yuzhnoy Sibiri: paleoekologicheskaya rekonstruktsiya po dannym antropologii [Ancient Cattle-Breeders of Southern Siberia: Palaeoecolocical Reconstruction on Anthropology Data]. Moscow, IA RAN, 1995. 220 p.

12. Mednikova M.B. Osteometricheskaya metodika v bioarkheologicheskikh rekonstruktsiyakh [Osteometric Method in Bioarchaeological Reconstructions]. Istoricheskaya ekologiya cheloveka. Metodika biologicheskikh issledovaniy [Historical Ecology of Man. Technique for Biological Study]. Moscow, Staryy Sad Publ., 1998, pp. 33-87.

13. Mednikova M.B. Antropo-ekologicheskie issledovaniya drevnego naseleniya Vostochnogo Priaralya [Anthropo-Ecological Studies of Ancient Population in Eastern Aral Region]. Gorizonty antropologii: tr. Mezhdunar. nauch. konf. pamyati akad. V.P. Alekseeva (Moskva, Saltykovka, 2022 sentyabrya 1994 g.) [Horizons of Anthropology. Proceedings of the International Scientific Conference in Memory of Academician V.P. Alekseev (Moscow, Saltykovka, September 20-22, 1994)]. Moscow, Nauka Publ., 2003, pp. 513-518.

14. Mednikova M.B. Paleoekologiya Tsentralnoy Azii po dannym antropologii [Palaeoecology of Central Asia by Anthropology Data]. Antropoekologiya Tsentralnoy Azii [Anthropoecology of Central Asia]. Moscow, Nauchnyy mir Publ., 2005, pp. 256-289.

15. Mednikova M.B. Fenomen iskusstvennoy deformatsii golovy: evraziyskiy kontekst [Phenomenon of Artificial Deformation of Head: Eurasian Context]. Iskusstvennaya deformatsiya golovy cheloveka $v$ proshlom Evrazii. OPUS: Mezhdistsiplinarnye issledovaniya $v$ arkheologii. Vyp. 5 [Artificial Deformation of Human Heads in the Past of Eurasia. OPUS: Interdisciplinary Research in Archaeology. Iss. 5]. Moscow, IA RAN, 2006, pp. 206-229.

16. Rykushina G.V. Materialy po odontologii Dzhetyasarskoy kultury. Gruntovye pogrebeniya mogilnikov Kosasar 2, Kosasar 3, Tompakasar, 


\section{МОРФОЛОГИЯ ДРЕВНИХ ПОПУЛЯЦИЙ}

Bedaikasar [Materials of Odontology of the Jetyasar Culture. Ground Graves of Kosasar 2, Kosasar 3, Tompakasar, Bedaikasasar Burial Sites]. Nizovya Syrdaryi v drevnosti. Vyp. 3. Dzhetyasarskaya kultura. Ch. 2 [Low Flow of the Syrdarya River in Antiquity. Iss. 3. Jetyasar Culture. Part 2]. Moscow, Institut etnologii i antropologii RAN, 1993, pp. 195-205.

17. Tolstov S.P. Po drevnim deltam Oksa $i$ Yaksarta [Along to Ancient Flows of Ox and Yaksart Rivers]. Moscow, Izd-vo vostochnoy literatury, 1962. $324 \mathrm{p}$.

18. Khodzhayov T. K. Etnicheskie protsessy v Sredney Azii v period srednevekovya [Ethnic Processes in Central Asia During the Middle Ages]. Tashkent, Fan Publ., 1987. 207 p.

19. Shvedchikova T.Yu. K voprosu o rasprostranenii obychaya iskusstvennoy deformatsii golovy u drevnego naseleniya Vostochnogo Priaralya [Concerning Distribution of Artificial Deformation Among Ancient Population of Eastern Aral Region]. Vestnik Moskovskogo universiteta. Seriya XXIII.
Antropologiya [Moscow University Anthropology Bulletin], 2009, no. 1, pp. 78-84.

20. Berner M., Kritscher H., Szilvassy J. Anthropologische Auswertung des Avarischen Graberfeldes von Munchendorf. Awaren Furshungen. Band 2. Wien, Institut fur Ur- und Fruhgeschichte, 1992, S. 1025-1193.

21. Buzhilova A.P., Mednikova M.B. Kosasar, an Ancient Population from the Eastern Aral Region: Palaeodemography, Osteometry, Growth Arrest. Homo, 1999, vol. 50 (1), pp. 66-79.

22. Ery K. Length of Limb Bones and Stature in Ancient Populations in the Carpatian Basin. Budapest, Humanbiologia Budapestinensis, 1998. 88 p.

23. Buzhilova A.P., Dobrovolskaya M.V., Mednikova M.B., Bogatenkov D.V., Lebedinskaya G.V. The Human Bones from Klin-Yar III and IV. Ritual, Society and Population at Klin-Yar (North Caucasus) Excavations 1994-1996 in the Iron Age to Early Medieval Cemetery. Berlin, Verlag Dr. Rudolf Habelt $\mathrm{GmbH}, 2018$, pp. 134-183.

\section{Information About the Authors}

Maria B. Mednikova, Doctor of Sciences (History, Archaeology), Leading Researcher, Institute of Archaeology RAS, Dm. Ulyanova St, 19, 117292 Moscow, Russian Federation, medma_pa@mail.ru, https://orcid.org/0000-0002-1918-2161

Anna A. Tarasova, Candidate of Sciences (History), Junior Researcher, Institute of Archaeology RAS, Dm. Ulyanova St, 19, 117292 Moscow, Russian Federation, taa-volga@yandex.ru, https://orcid.org/0000-0001-5469-2629

Olga Yu. Chechyotkina, PhD Student, Institute of Archaeology RAS, Dm. Ulyanova St, 19, 117292 Moscow, Russian Federation, chechyotkina91@bk.ru, https://orcid.org/0000-0002-4880-1080

\section{Информация об авторах}

Мария Борисовна Медникова, доктор исторических наук, ведущий научный сотрудник, Институт археологии РАН, ул. Дм. Ульянова, 19, 117292 г. Москва, Российская Федерация, medma_pa@mail.ru,https://orcid.org/0000-0002-1918-2161

Анна Анатольевна Тарасова, кандидат исторических наук, младший научный сотрудник, Институт археологии РАН, ул. Дм. Ульянова, 19, 117292 г. Москва, Российская Федерация, taa-volga@yandex.ru, https://orcid.org/0000-0001-5469-2629

Ольга Юрьевна Чечеткина, аспирант, Институт археологии РАН, ул. Дм. Ульянова, 19, 117292 г. Москва, Российская Федерация, chechyotkina91@bk.ru, https://orcid.org/0000-0002-4880-1080 